\title{
Temporal Contrast Adaptation in Salamander Bipolar Cells
}

\author{
Fred Rieke \\ Department of Physiology and Biophysics, University of Washington, Seattle, Washington 98195
}

This work investigates how the light responses of salamander bipolar cells adapt to changes in temporal contrast: changes in the depth of the temporal fluctuations in light intensity about the mean. Contrast affected the sensitivity of bipolar cells but not of photoreceptors or horizontal cells, suggesting that adaptation occurred in signal transfer from photoreceptors to bipolars. This suggestion was confirmed by recording from photoreceptor-bipolar pairs and observing a direct dependence of the gain of signal transfer on the contrast of the light input. After an increase in contrast, the onset of adaptation in the bipolar cell had a time constant of 1-2 sec, similar to a fast component of contrast adaptation in the light responses of retinal ganglion cells (Kim and Rieke, 2001). Contrast adaptation was mediated by processes in the dendrites of both on and OFF bipolars. The functional properties of adaptation differed for the two bipolar types, however, with contrast having a much more pronounced effect on the kinetics of the responses of OFF cells than on cells.

Key words: contrast gain control; contrast adaptation; bipolar cell; adaptation; temporal contrast; retinal signal processing
A general problem sensory neurons face is adjusting their operational range to match the range of the input signals they receive. This is particularly clear for vision, in which the mean light intensity and the contrast (the extent of fluctuations in light intensity about the mean) vary substantially in different visual environments. The visual system handles these differences in input signals by adjusting its sensitivity, or adapting. Adaptation includes mechanisms sensitive to the mean light intensity (for review, see Walraven et al., 1990) and the spatial and temporal contrast (for review, see Shapley, 1997; Meister and Berry, 1999). This work examines the contribution of retinal bipolar cells to temporal contrast adaptation.

Contrast adaptation is widely viewed as a cortical phenomena, and there is good evidence that cortical mechanisms contribute (Albrecht et al., 1984; Ohzawa et al. 1985; Sanchez-Vives et al., 2000). Several studies, however, show that changes in temporal contrast affect the sensitivity of retinal ganglion cells in amphibians and mammals (Sakai et al., 1995; Smirnakis et al., 1997), including primate (Chander and Chichilnisky, 1999, 2001). Indeed, without contrast adaptation, many retinal neurons would be easily saturated because of their high contrast gain (Capovilla et al., 1987; Burkhardt and Fahey, 1998, 1999). Thus, the retina makes an important contribution to the ability of the visual to adapt to contrast. We know little, however, about where contrast adaptation occurs in the retina or what mechanisms are responsible.

Retinal contrast adaptation shows a range of spatial and temporal properties: the spatial extent of the signal controlling contrast adaptation differs between ON and OFF ganglion cells (Smirnakis et al., 1997); the onset of adaptation after an increase in contrast has several temporal components (Victor, 1987; Sakai et

Received March 6, 2001; revised Sept. 10, 2001; accepted Sept. 13, 2001.

This work was supported by National Institutes of Health Grant EY-11850 and the McKnight Foundation. I thank Cecilia Armstrong, Divya Chander, E. J. Chichilnisky, Greg Field, Josh Gold, Kerry Kim, and Maria McKinley for helpful discussions and Eric Martinson for excellent technical assistance.

Correspondence should be addressed to Dr. Fred Rieke at the above address. E-mail: rieke@u.washington.edu.

Copyright (ㄷ) 2001 Society for Neuroscience $0270-6474 / 01 / 219445-10 \$ 15.00 / 0$ al., 1995; Smirnakis et al., 1997; Kim and Rieke, 2001); and the strength of contrast adaptation differs between ON and OFF ganglion cells (Chander and Chichilnisky, 1999; Kim and Rieke, 2001). This diversity in the properties of contrast adaptation in the retinal output suggests a corresponding diversity in both the mechanisms mediating contrast adaptation and in the functional roles of each mechanism.

We found previously that contrast adaptation included contributions from spike generation in retinal ganglion cells and from unidentified sites within the retinal circuitry (Kim and Rieke, 2001). The aim of the present work was to identify the sites of contrast adaptation in the retinal circuitry and the mechanisms responsible. The principal findings described here are as follows: (1) the first site of contrast adaptation in the retina is in the dendrites of bipolar cells; (2) this site contributes to the fast-onset component of contrast adaptation seen in retinal ganglion cells (Kim and Rieke, 2001); and (3) the functional properties of contrast adaptation differ between ON and OFF bipolars, with contrast exerting a larger effect on the kinetics of the responses of OFF cells than ON cells.

\section{MATERIALS AND METHODS}

Recording procedures. All experiments used retinas from larval tiger salamanders (Ambystoma tigrinum; from Charles Sullivan, Nashville, $\mathrm{TN})$. Salamanders were dark adapted overnight, and retinas were isolated under infrared light (Kim and Rieke, 2001) following procedures approved by the Administrative Panel on Laboratory Animal Care at the University of Washington.

Light-evoked current and voltage responses of retinal cells were measured in a slice preparation. A piece of retina $\sim 1 \times 2 \mathrm{~mm}$ was embedded in low gelling temperature agar (Sigma, St. Louis, MO), immersed in cold HEPES-buffered Ames medium (Sigma), and sliced in $300-\mu \mathrm{m}$ thick sections on a vibrating microtome (Leica, Wetzlar, Germany). Slices were transferred to a recording chamber and held in place with a coarse nylon grid glued to a platinum weighting ring. The chamber was placed on the stage of an upright microscope equipped with an infrared viewing system. Slices were continuously superfused with a bicarbonate Ringer's solution containing (in mM): $110 \mathrm{NaCl}, 2 \mathrm{KCl}, 30 \mathrm{NaHCO}_{3}, 1.5$ $\mathrm{CaCl}_{2}, 1.6 \mathrm{MgCl}_{2}$, and 10 glucose; $\mathrm{pH}$ was 7.4 when equilibrated with $5 \%$ $\mathrm{CO}_{2}-95 \% \mathrm{O}_{2}$ and osmolarity was $270-275 \mathrm{mOsm}$. The volume of the recording chamber was $\sim 300 \mu \mathrm{l}$, and the superfusion rate was $1-2$ $\mathrm{ml} / \mathrm{min}$. All experiments were at $20-22^{\circ} \mathrm{C}$. 
Light produced by a light-emitting diode (LED) was focussed on the slice through the bottom of the recording chamber. An LED with a peak output at $470 \mathrm{~nm}$ was used to stimulate rods, and one with a peak output at $640 \mathrm{~nm}$ was used to stimulate L cones. The light stimuli were spatially uniform and illuminated a circular area $650 \mu \mathrm{m}$ in diameter centered on the recorded cell. The temporal contrast of the light stimulus was controlled by adding Gaussian fluctuations to the signal controlling the light output of the LED. The Gaussian fluctuations were low-pass filtered at either 10 (for rods) or 30 (for cones) $\mathrm{Hz}$, as noted in the figure legends. The contrast of this stimulus was defined as the SD of the light intensity divided by the mean. Light intensities measured at the preparation are given in the figure legends.

Electrical responses were measured using either perforated-patch or whole-cell recordings and an Axopatch 200B patch-clamp amplifier (Axon Instruments, Foster City, CA); recording configurations are noted in the figure legends. Patch pipettes were filled with an internal solution containing (in mM): $125 \mathrm{~K}$-aspartate, $10 \mathrm{KCl}, 10 \mathrm{HEPES}, 5 \mathrm{~N}$ methylglucamine (NMG)-N-hydroxyethylethylenediaminetriacetic acid (HEDTA), $1 \mathrm{CaCl}_{2}, 1 \mathrm{ATP}, 0.1 \mathrm{GTP}$, and $0.1 \mathrm{~mm}$ calcein, $\mathrm{pH}$ was adjusted to 7.2 with NMG-OH (and osmolarity was $260-265 \mathrm{mOsm}$ ). For perforated-patch recordings, the pipette solution also contained $1 \mathrm{mg} / \mathrm{ml}$ amphotericin-B (solubilized formulation; Sigma), and the pipette tip was filled with amphotericin-free solution. Filled pipettes had resistances of 8-10 $\mathrm{M} \Omega$, and the series resistance during recording was $20-40 \mathrm{M} \Omega$. Calcein was included in the pipette solution to permit the morphology of a cell to be visualized under fluorescence at the end of a recording; all bipolar cells reported here had processes in both the inner and outer plexiform layers. ON and OFF bipolars were distinguished based on the polarity of their responses to $1 \mathrm{sec}$ light increments and decrements (see Fig. 6 , insets). In voltage-clamp recordings, bipolar cells were held at -60 $\mathrm{mV}$; in current-clamp recordings, the holding current was between 0 and $-50 \mathrm{pA}$, resulting in a membrane potential near $-50 \mathrm{mV}$. Voltages have not been corrected for junction potentials (approximately -9 to $-10 \mathrm{mV}$ for the solutions used).

Data analysis. The effect of contrast on the amplitude and kinetics of the light response of a cell was measured using a static nonlinearity model that provided a relatively simple description of how continuous light inputs were transformed into cellular responses (Sakai et al., 1995; Chichilnisky, 2001). An important aspect of this model is that it separates an instantaneous nonlinearity in the response of a cell (e.g., attributable to saturation or activation of voltage-dependent conductances) from a change in the response characteristics of a cell attributable to adaptation. The model describes the current-to-response transformation as a linear filter followed by a static or time-independent nonlinearity (Fig. 1A). Comparing the filter and static nonlinearity for lights of different contrasts proved an effective means of characterizing contrast-dependent changes in the amplitude and kinetics of the light response of a cell. Details of the calculation of the linear filter and static nonlinearity are described by Kim and Rieke (2001).

The linear filter and static nonlinearity were determined from recordings of 5-10 min of the response of a cell to light inputs of a given contrast. Figure 1 shows an example of this analysis for responses of a current-clamped on bipolar cell to a $30 \%$ contrast light input. Figure $1 B$ shows the linear filter; convolving this filter with the light input provides the best linear estimate of the voltage response of a cell given the light input (Wiener, 1949; Kim and Rieke, 2001). Thus, the shape of the filter estimates the time course of the response of a cell to a brief light flash at time 0 in the presence of the fluctuating contrast signal. For ON cells such as that in Figure $1 B$, the linear filter measured under current clamp has a positive polarity, reflecting the depolarization produced by an increment in light intensity (Fig. $1 B$, inset). Systematic differences between the measured voltage and the linear prediction obtained by convolving the light input with the linear filter were used to determine a timeindependent nonlinearity in the relationship between light input and the response of a cell: the static nonlinearity in the model. The shape of the static nonlinearity was determined by calculating the average measured response for each value of the linear prediction. Figure $1 C$ plots the average measured response ( $y$-axis) against the corresponding linear prediction ( $x$-axis). In this cell, as in most bipolars, the nonlinearity was mild and consisted primarily of a gradual decrease in slope for large response amplitudes.

Figure $1 D$ compares a short section of the measured voltage response with the prediction from the linear filter and static nonlinearity in Figure $1, B$ and $C$. Although the prediction captures much of the structure in the measured response, there are also clear differences. In principle, these
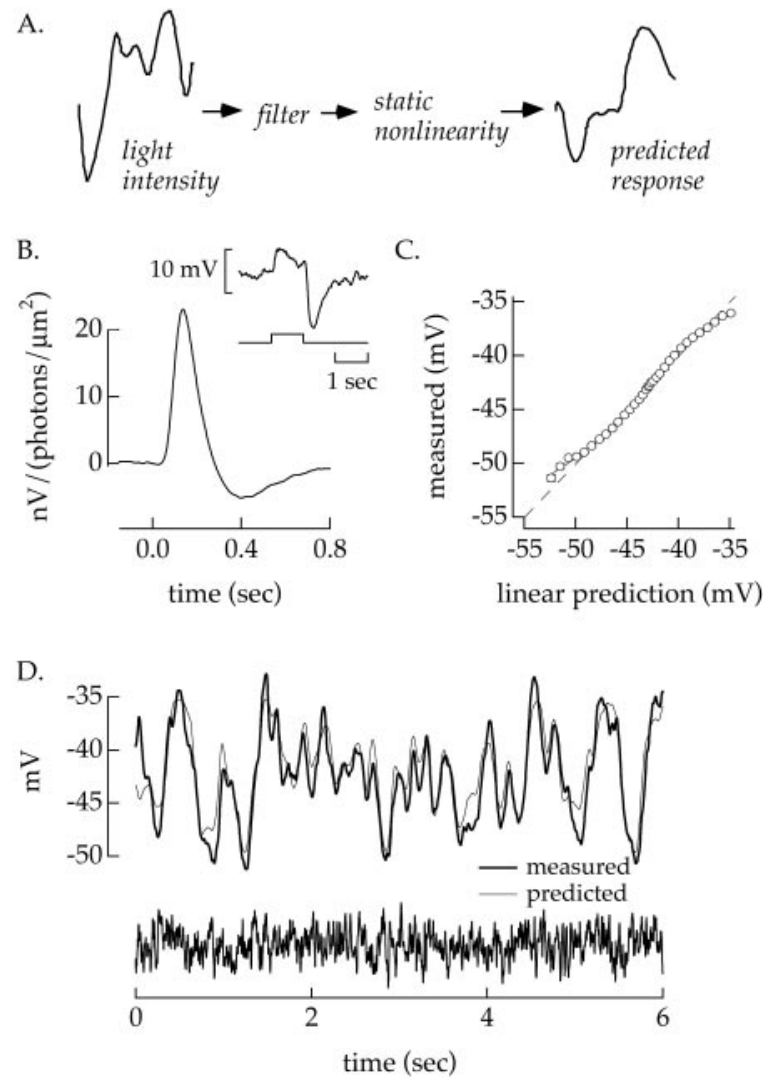

Figure 1. Static-nonlinearity model. $A$, The transformation between light inputs and cellular response was described using a model consisting of a linear filter followed by a time-independent or static nonlinearity. The filter and static nonlinearity were calculated from recordings of 5-10 min of the response of a cell to a fluctuating light input. $B$, Linear filter for a current-clamped on bipolar cell stimulated with a $30 \%$ contrast light input. The inset shows the response of a cell to a $1 \mathrm{sec}$ light step. $C$, Static nonlinearity determined by plotting the measured response against the linear prediction formed by convolving the light input with the linear filter in $B$. Each point represents the average measured current ( $y$-axis) for a particular value of the linear prediction ( $x$-axis). Error bars are SE and are mostly obscured by the data points. $D$, Short section of the measured and predicted response. Mean light intensity, 20,300 photons $\mu \mathrm{m}^{-2} \mathrm{sec}^{-1}$ using $640 \mathrm{~nm}$ LED; bandwidth, $0-30 \mathrm{~Hz}$. Holding current, $0 \mathrm{pA}$. Perforated-patch recording.

differences could reflect either noise in the measured response or a failure of the model. To distinguish between these possibilities, differences in the individual measured responses to a repeated stimulus were compared with differences between the measured and predicted response. The extent of trial-to-trial fluctuations in the response of a cell was determined by measuring the correlation between the average response and the individual responses to $15-30$ repeats of a $20 \mathrm{sec}$ stimulus. In four such experiments, the average correlation was 0.76 . This correlation was compared with the average correlation between the response predicted by the static nonlinearity model and the individual measured responses, which was 0.70 in the same four cells. Thus, $>90 \%$ of the light-dependent structure in the measured response was well predicted by the static nonlinearity model.

The model of Figure 1 was used to study contrast adaptation by comparing linear filters and static nonlinearities measured for light inputs of two contrasts. In all cells analyzed, the effect of contrast could be restricted to changes in the linear filter, greatly simplifying interpretation of the results. For a given contrast, the linear filter and static nonlinearity are unique up to a single scale factor. Thus, both the $y$-axis scaling of the filter in Figure $1 B$ and the $x$-axis scaling of the static nonlinearity in Figure $1 C$ can be multiplied by a factor $\alpha$ without changing the prediction of the model, because the rescaling of the filter amplitude is offset by the change in the static nonlinearity. When linear 
filters and static nonlinearities for two contrasts were compared, $\alpha$ was chosen to produce the best overlap of the static nonlinearities (Chichilnisky, 2001; Kim and Rieke, 2001). For example, Figure 3D-F shows nonlinearities for a cone, horizontal cell, and OFF bipolar cell measured at 10 and $30 \%$ contrast. In each case, $\alpha$ was chosen to cause the static nonlinearities to overlap and thus restrict the effect of contrast to changes in the linear filter. A similar scaling was used each time contrast adaptation was quantified using the static nonlinearity model. Thus, the transformation of light inputs into cellular responses was described as a contrast-dependent linear filter followed by a contrast-independent static nonlinearity.

\section{RESULTS}

The experiments described below indicate that signal transfer from rods and cones to bipolar cells provides the first site of contrast adaptation in the retina. The onset and offset of this adaptation were relatively rapid and contributed to a fast-onset component of contrast adaptation in retinal ganglion cells. Contrast adaptation differed both functionally and mechanistically in ON and OFF bipolars.

\section{Bipolar cells provide the first site of contrast adaptation}

Two results indicate that the light responses of bipolar cells adapt to the contrast of the light input but that those of photoreceptors and horizontal cells do not. First, after an increase in contrast, the amplitude of the light response of a bipolar immediately increased and then gradually declined, suggesting a time-dependent change in sensitivity induced by the contrast change. Second, the steady-state sensitivity of the light responses of bipolar cells decreased after an increase in contrast. Both effects were small or absent in photoreceptors and horizontal cells.

\section{Response time course after a change in contrast}

A signature of adaptation is a change in sensitivity over time after a change in the input signal. Thus, contrast adaptation should cause gradual changes in the amplitude of the response of a cell after a change in contrast. To test for such changes, a randomly fluctuating light stimulus was switched between 10 and $30 \%$ contrast every $20 \mathrm{sec}$ while recording the resulting response in a photoreceptor, horizontal cell, or bipolar cell. Figure $2 A-C$ shows voltage recordings from a cone $(A)$, horizontal cell $(B)$, and OFF bipolar cell $(C)$ to a single cycle of this alternating contrast signal. The timing of the contrast change is shown in the stimulus trace at the bottom of the figure.

The amplitude of the light responses of photoreceptors and horizontal cells changed quickly after an increase $(0 \mathrm{sec})$ or decrease $(20 \mathrm{sec})$ in contrast and did not show time-dependent structure that would suggest the cells were adapting. The absence of time-dependent structure was captured more clearly by measuring the time-dependent variance across 15-30 cycles of the contrast signal. Independent stimuli were used in each cycle, and thus the variance measured the strength of the response of a cell to the fluctuating stimulus. In both photoreceptors (Fig. 2D) and horizontal cells (Fig. 2E), the variance reached a steady-state level within $\sim 0.2 \mathrm{sec}$ after a change in contrast and maintained this level throughout the $20 \mathrm{sec}$ duration of the contrast signal. A similar lack of time dependence was observed in the responses of four rods, eight cones, and six horizontal cells.

The responses of bipolar cells, on the other hand, did show time-dependent structure. After an increase in contrast, the amplitude (Fig. 2C) and the variance (Fig. $2 F$ ) of the response increased rapidly and then declined to a steady level; after a decrease in contrast, the variance fell to an initial minimum and

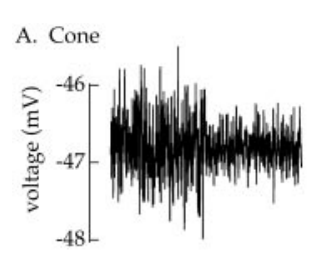

D.
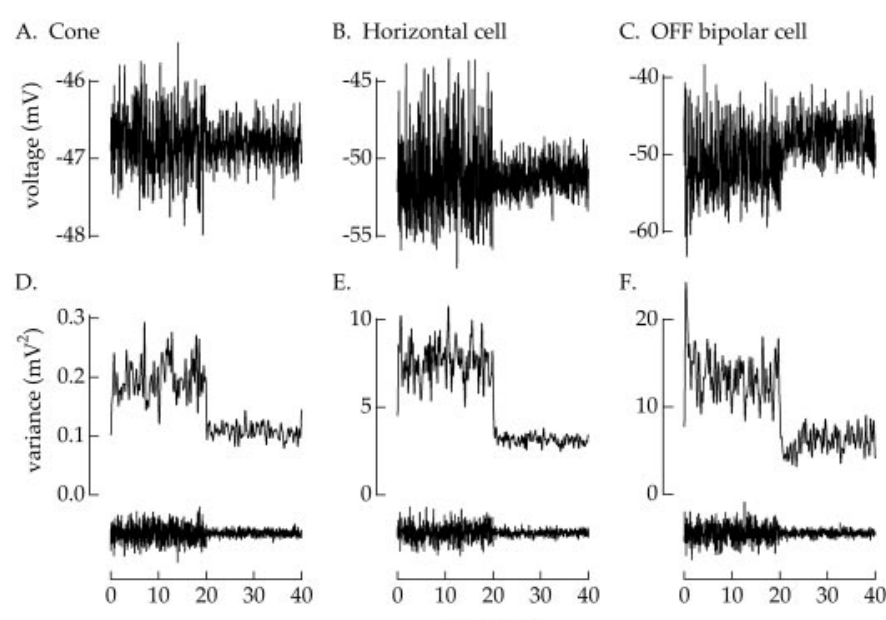

E.
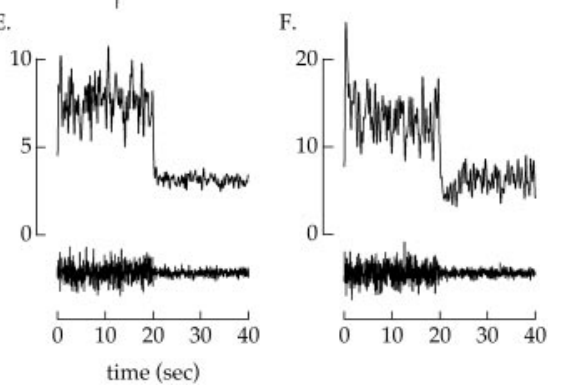

Figure 2. Cone, horizontal, and bipolar responses to an alternating contrast signal. The stimulus alternated between 30 and $10 \%$ contrast every $20 \mathrm{sec}$ (see stimulus trace at bottom). Current-clamp responses to a single cycle of this stimulus are shown in $A$ for a cone, $B$ for a horizontal cell, and $C$ for an ofF bipolar cell. The time dependence of the amplitude of the response of each cell to the fluctuating contrast stimulus was measured by calculating the time-dependent variance from 15-30 cycles of the stimulus. The fluctuating stimulus was independent in each cycle. The variance is shown in $D$ for the cone, $E$ for the horizontal cell, and $F$ for the bipolar. The variance measured in the cone and horizontal cell showed little time-dependent structure after a change in contrast, whereas the variance measured in the bipolar cell showed transients after increases (at $t=0$ ) and decreases (at $t=20 \mathrm{sec}$ ) in contrast. Mean light intensity, 18,800 photons $\mu \mathrm{m}^{-2} \mathrm{sec}^{-1}$ for the cone and bipolar cell and 18,200 photons $\mu \mathrm{m}^{-2} \mathrm{sec}^{-1}$ for the horizontal cell (all using $640 \mathrm{~nm}$ LED). Holding currents: $-50 \mathrm{pA}$ for the cone, $0 \mathrm{pA}$ for the horizontal, and $0 \mathrm{pA}$ for the bipolar. Perforated-patch recordings.

then gradually increased. A similar time dependence was observed in nine bipolar cells. These results suggest that bipolar cells adapt to temporal contrast.

\section{Contrast-dependent changes in sensitivity}

The static nonlinearity model (see Materials and Methods) (Fig. 1) was used to determine how contrast affected the gain and kinetics of the responses of photoreceptors, horizontal cells, and bipolar cells. This model predicts the response of a cell to continuous light inputs of a particular contrast by passing the light intensity through a linear filter followed by a time-independent or static nonlinearity (Fig. 1). The linear filter (Fig. 3A) estimates the time course of the response of a cell to a brief light flash in the presence of a fluctuating contrast signal. Thus, for the cone in Figure $3 A$, the filter predicts that the cell would respond to a brief light flash at time 0 with a hyperpolarization lasting $\sim 0.2 \mathrm{sec}$. The static nonlinearity (Fig. 3D) describes the relationship between the output of this linear filter and the measured response. In general, this relationship is nonlinear, reflecting processes such as saturation or activation of cellular conductances. This model provided a relatively compact description (a single filter and time-independent nonlinearity) of how the cell responded to light inputs of a particular contrast. A key aspect of this model is that it separates instantaneous nonlinearities in the response of a cell from changes in sensitivity attributable to adaptation.

Contrast-dependent changes in the amplitude and kinetics of the response of a cell were measured by comparing filters and nonlinearities for different contrast inputs. High- and low-contrast stimuli were interleaved to ensure that adaptation was reversible. A section of record after each change in contrast was discarded to 


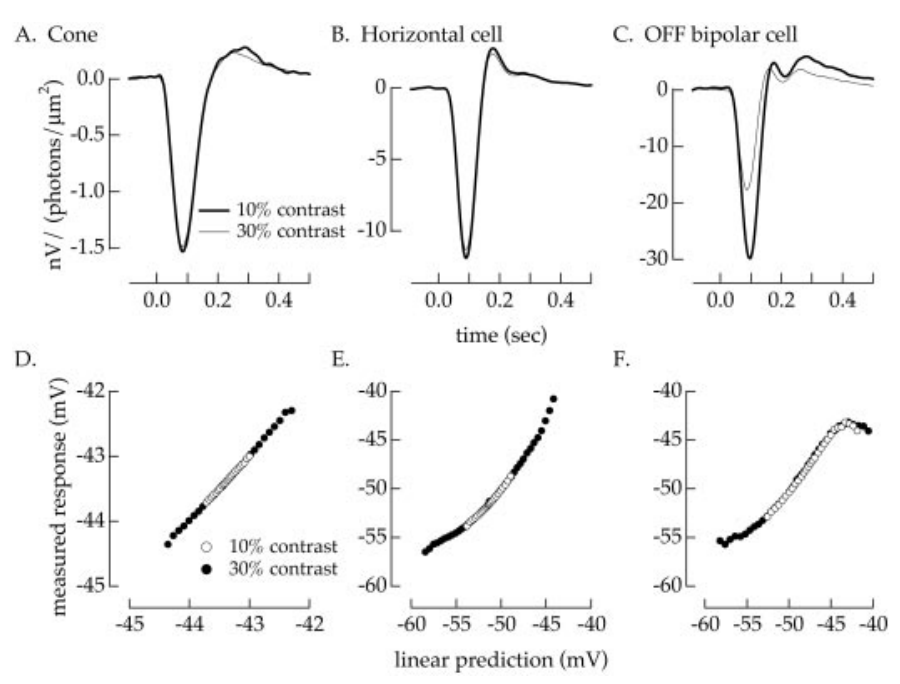

Figure 3. Contrast adaptation in a current-clamped cone, horizontal cell, and ofF bipolar cell measured using the static nonlinearity model. Same cells and recording conditions as Figure 2. The contrast was alternated between 10 and $30 \%$ every $20 \mathrm{sec}$. Linear filters and static nonlinearities were calculated from 15-30 cycles of this stimulus, excluding the first $4 \mathrm{sec}$ of record after a change in contrast. Linear filters measured for $10 \%$ (thick trace) and $30 \%$ (thin trace) contrast stimuli are shown in $A$ for the cone, $B$ for the horizontal cell, and $C$ for the OFF bipolar cell. Static nonlinearities are shown in $D$ for the cone, $E$ for the horizontal cell, and $F$ for the bipolar cell. In each case, the static nonlinearities at 10 and $30 \%$ contrast overlapped and hence did not contribute to contrast adaptation. Linear filters at 10 and $30 \%$ contrast were similar in the cone and horizontal cell but differed substantially in the bipolar.

permit the response of a cell to reach steady state. Figure $3 A-C$ shows linear filters measured at 10 and $30 \%$ contrast for the cone, horizontal cell, and OFF bipolar cell from Figure 2. Figure $3 D-F$ plots the corresponding static nonlinearities. In each cell, the nonlinearities had similar shapes at high and low contrast and thus did not contribute to contrast-dependent changes in sensitivity (see Materials and Methods). A similar contrast independence of the shape of the static nonlinearity was found in all of the photoreceptors, horizontal cells, and bipolar cells studied. This greatly simplified characterization of contrast adaptation as the effect of contrast on the response of a cell was restricted to changes in the linear filter. In subsequent figures, the static nonlinearities are not shown, and the linear filters at high and low contrast are scaled by a common factor so that the filter at low contrast has unit amplitude.

Linear filters measured at 10 and $30 \%$ contrast were nearly identical in cones (Fig. 3A) and horizontal cells (Fig. 3B) but differed considerably in bipolar cells (Fig. $3 C$ ). The ratio of the amplitude of the filter at high and low contrast was $0.98 \pm 0.04$ (mean \pm SEM) in four rods, $1.01 \pm 0.04$ in eight cones, $0.96 \pm$ 0.03 in six horizontal cells, and $0.79 \pm 0.02$ in 42 bipolar cells. Contrast had a similar effect on the light responses of current- and voltage-clamped bipolar cells (see Fig. 8); thus, in most experiments, cells were voltage clamped to minimize the effects of voltage-activated conductances. Experiments like those illustrated in Figure 3 show that the sensitivity of photoreceptors and horizontal cells changed little after a change in contrast, whereas the sensitivity of bipolar cells changed substantially.

\section{Contrast affects the gain of photoreceptor-bipolar signal transfer}

The experiments of Figures 2 and 3 indicate that bipolar cells, but not photoreceptors or horizontal cells, adapt to temporal con-
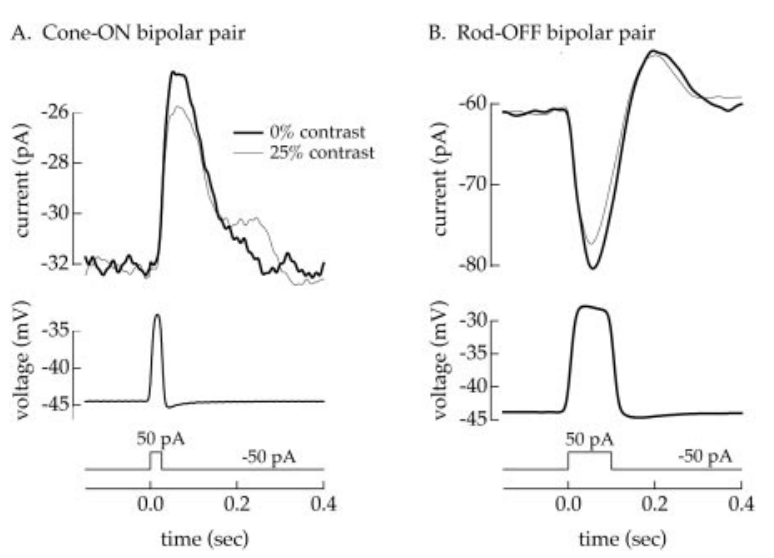

Figure 4. Contrast affected gain of signal transfer from photoreceptors to bipolars. The gain of signal transfer was measured by injecting depolarizing current into the photoreceptor and measuring the resulting postsynaptic response in the bipolar cell. This was repeated in the presence and absence of a $25 \%$ contrast light input. $A$, Measurements from a current-clamped cone and voltage-clamped on bipolar cell. The cone current was stepped from -50 to $+50 \mathrm{pA}$ for $20 \mathrm{msec}$, and the average change in cone voltage (bottom) and bipolar current (top) was measured. The voltage change in the cone was essentially identical in the presence (thin trace) and absence (thick trace) of the contrast stimulus. The bipolar response to depolarization of the cone decreased in the presence of the contrast stimulus, indicating a contrast-dependent change in the gain of signal transfer. Mean light intensity, 18,800 photons $\mu \mathrm{m}^{-2} \mathrm{sec}^{-1}$ using $640 \mathrm{~nm}$ LED; bandwidth, 0-30 Hz. Bipolar holding potential, $-60 \mathrm{mV} . B$, Measurements from a current-clamped rod and voltage-clamped oFF bipolar cell. The bipolar response to stepping the rod holding current from -50 to $+50 \mathrm{pA}$ decreased in the presence of a $25 \%$ contrast light stimulus, indicating a change in the gain of signal transfer. Mean light intensity, 22 photons $\mu \mathrm{m}^{-2} \mathrm{sec}^{-1}$ using $470 \mathrm{~nm}$ LED; bandwidth, $0-10$ $\mathrm{Hz}$. Bipolar holding potential, $-60 \mathrm{mV}$. Perforated-patch recordings.

trast, suggesting that contrast affects the gain of signal transfer from photoreceptors to bipolar cells. Simultaneous recordings from photoreceptors and bipolar cells provided direct evidence for this conclusion by bypassing the phototransduction process and measuring the gain of signal transfer directly.

The gain of signal transfer was measured by injecting a depolarizing current pulse into a photoreceptor and measuring the resulting postsynaptic response in a bipolar cell. This experiment was repeated in the presence and absence of a $25 \%$ contrast light input, and the gain of signal transfer was compared in the two conditions. No attempt was made to disrupt gap junctions, so the bipolar response represents changes in transmitter release from a collection of electrically coupled photoreceptors (Schwartz, 1976; Attwell et al., 1984). A similar spread of signals among coupled photoreceptors occurs under normal conditions in the retina.

Figure $4 A$ shows results from a cone-ON bipolar pair in which the cone was current clamped and the bipolar was voltage clamped. Throughout the experiment, the slice was exposed to bright $640 \mathrm{~nm}$ light. Changing the holding current of the cone from -50 to $+50 \mathrm{pA}$ for $20 \mathrm{msec}$ depolarized the cone and produced a postsynaptic response in the bipolar cell. Sets of 20 such current pulses delivered in the presence and absence of a $25 \%$ contrast light input were interleaved. The bottom panel of Figure $4 A$ shows average voltage changes in the cone in response to the current pulse. Responses in the presence and absence of the contrast stimulus are superimposed. Neither the mean cone voltage nor the voltage change produced by the current pulse was affected by the contrast signal. The top panel of Figure $4 A$ shows the response of the bipolar to current injected into the cone. The 
bipolar response was smaller in the presence of the contrast signal than in its absence, indicating a contrast-dependent change in the gain of signal transfer.

Figure $4 B$ shows results from a similar experiment on a rodOFF bipolar pair. In this case, the experiment was performed in the presence of $470 \mathrm{~nm}$ light, which produced responses in rods but was too dim to elicit responses in cones. The bottom panel of Figure $4 B$ shows the average voltage response in the rod when the holding current was changed from -50 to $+50 \mathrm{pA}$ for $100 \mathrm{msec}$. Responses in the presence and absence of a $25 \%$ contrast light input are superimposed. Again, the contrast stimulus had little or no effect on either the mean rod voltage or the voltage response to the current pulse. The top panel in Figure $4 B$ shows the bipolar response to current injected into the rod. As for the cone-bipolar pair, the bipolar response was smaller in the presence of the contrast signal. Contrast also appeared to speed the kinetics of signal transfer from the rod to the ofF bipolar, as observed for the light responses of OFF bipolars (see Fig. 6).

A similar contrast dependence of the gain of signal transfer was observed in four cone-bipolar and six rod-bipolar pairs. The contrast dependence of signal transfer could be produced by either presynaptic or postsynaptic mechanisms. Because horizontal cells and bipolar cells both receive direct input from photoreceptors, the lack of contrast adaptation in horizontal cells (Fig. $3 B$ ) suggests that the changes in signal transfer are not a property of presynaptic mechanisms in the photoreceptor synaptic terminal but are generated postsynaptically in the bipolar cell. Additional evidence for this conclusion is provided by the experiments of Figure 10 described below.

\section{Properties of contrast adaptation in bipolar cells}

\section{Time course of onset and offset}

The onset and offset of contrast adaptation in the retina occur on several time scales (Victor, 1987; Sakai et al., 1995; Smirnakis et al., 1997; Kim and Rieke, 2001). For example, the onset of contrast adaptation in salamander retinal ganglion cells includes components with $\sim 1$ and $\sim 10 \mathrm{sec}$ time constants (Kim and Rieke, 2001). To determine the kinetics of the onset and offset of contrast adaptation in bipolar cells, the contrast was switched between 10 and $30 \%$ periodically, and the time-dependent variance of the resulting bipolar response was measured. Figure 5 shows the variance in the current response of a voltage-clamped OFF bipolar cell for contrast switches every $10 \mathrm{sec}$. The changes in the variance after increases $(t=0)$ and decreases $(t=10 \mathrm{sec})$ in contrast were fit by single exponentials (Fig. 5, smooth curves). The time constants for the onset and offset of contrast adaptation in this cell were 2.1 and $6.2 \mathrm{sec}$. In nine cells, the onset of contrast adaptation had a time constant of $1.8 \pm 0.3 \mathrm{sec}($ mean \pm SEM), and the offset had a time constant of $4.7 \pm 0.8 \mathrm{sec}$. The input currents to ganglion cells exhibited a similar asymmetry between the kinetics of the onset and offset of contrast adaptation (Kim and Rieke, 2001). Bipolar cells, however, showed no evidence for a slower temporal component after an increase in contrast like that seen in ganglion cells. Thus, bipolar cells contribute to the fast-onset component of contrast adaptation observed in the ganglion cells.

\section{ON and OFF bipolars adapt differently to contrast}

Contrast adaptation differed in ON and OFF bipolar cells. Although contrast affected the amplitude of the light responses in both types of bipolar cell, the effect of contrast on the response kinetics was pronounced in OFF bipolars and small or absent in ON bipo-

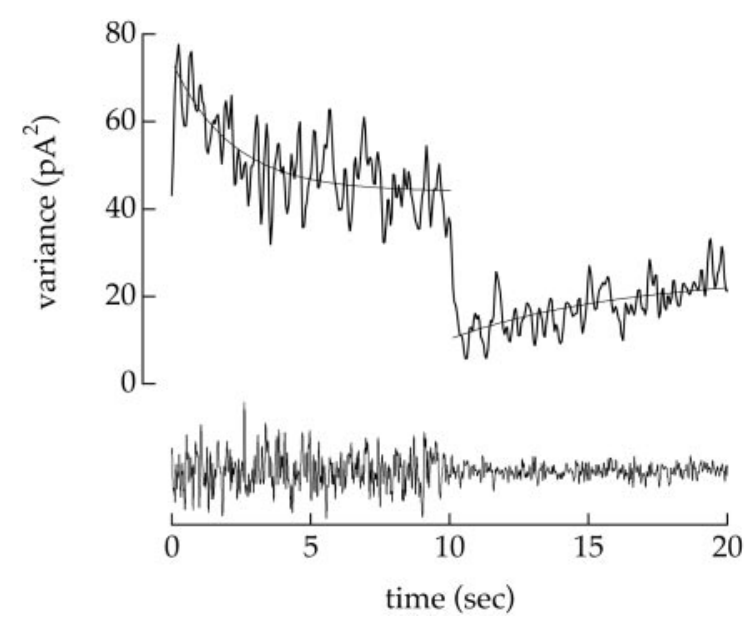

Figure 5. Kinetics of onset and offset of contrast adaptation. An OFF bipolar cell was voltage clamped while the contrast of the light input was switched between 10 and $30 \%$ every $10 \mathrm{sec}$. The time-dependent variance was computed from 21 repetitions of this stimulus. The smooth curves fit to the variance are single exponentials, with time constants of $2.1 \mathrm{sec}$ (fit between 0 and $10 \mathrm{sec}$ ) and $6.2 \mathrm{sec}$ (fit between 10 and $20 \mathrm{sec}$ ). Mean light intensity, 18,200 photons $\mu \mathrm{m}^{-2} \mathrm{sec}^{-1}$ using $640 \mathrm{~nm}$ LED; bandwidth, $0-30 \mathrm{~Hz}$. The bipolar holding potential was $-60 \mathrm{mV}$, resulting in a -70 pA average current. Perforated-patch recording.
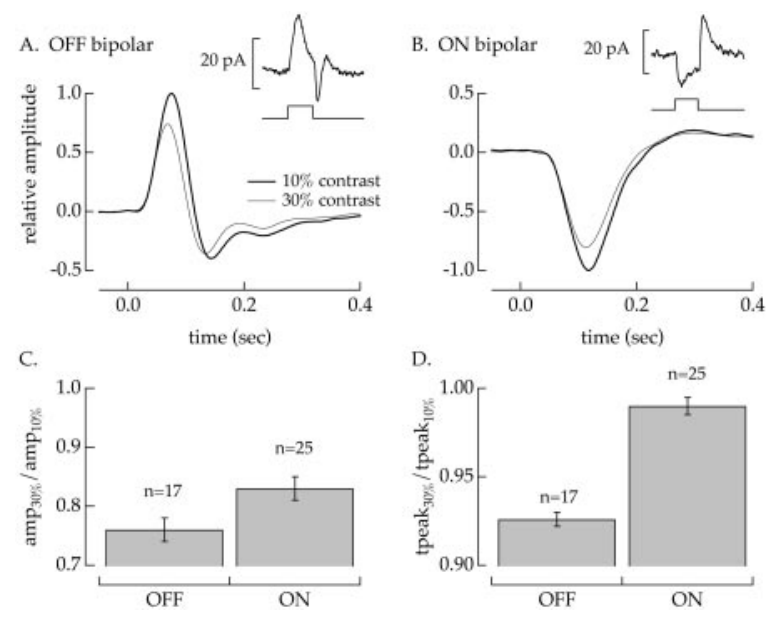

Figure 6. Contrast adaptation differed in ON and OFF bipolar cells. Contrast adaptation was measured for 10 and $30 \%$ contrast light inputs using the static nonlinearity model as in Figures 1 and 3. Linear filters measuring the amplitude and kinetics of the current response of a cell are shown in $A$ for a voltage-clamped OFF bipolar and in $B$ for a voltageclamped on bipolar. Insets show responses to $1 \mathrm{sec}$ light steps. The holding potential in both cases was $-60 \mathrm{mV}$, resulting in a current of $-60 \mathrm{pA}$ in the OFF bipolar and $-90 \mathrm{pA}$ in the oN bipolar. Mean light intensity, 17,800 photons $\mu \mathrm{m}^{-2} \mathrm{sec}^{-1}$ in $A$ and 18,200 photons $\mu \mathrm{m}^{-2} \mathrm{sec}^{-1}$ in $B$, both using $640 \mathrm{~nm}$ LED. $C$, Collected measures of the amplitude of the filter at $30 \%$ contrast relative to that at $10 \%$ contrast for 17 OFF bipolars and 25 ON bipolars. Error bars are SEM. D, Collected measures of the time-topeak of the filter at $30 \%$ contrast relative to that at $10 \%$ contrast. Perforated-patch recordings.

lars. ON and OFF bipolars were distinguished based on their responses to $1 \mathrm{sec}$ light increments. Under voltage clamp, a light increment generated an outward current in an OFF bipolar (Fig. $6 A$, inset) and an inward current in an on bipolar (Fig. 6B, inset). No attempt was made to divide ON and OFF bipolars into subtypes (Burkhardt and Fahey, 1998; Wu et al., 2000).

Contrast adaptation was measured by presenting 10 and $30 \%$ 
contrast inputs and characterizing the amplitude and kinetics of the light response of a cell using the static nonlinearity model. Figure 6 shows linear filters for an OFF bipolar (Fig. 6A) and an ON bipolar (Fig. $6 B$ ), both measured under voltage clamp. The static nonlinearities did not change with contrast (data not shown), and thus contrast adaptation was restricted to changes in the linear filters. In the OFF bipolar, increasing the contrast from 10 to $30 \%$ decreased the amplitude and the time-to-peak of the filter. In the ON bipolar, increasing the contrast from 10 to $30 \%$ produced a clear change in amplitude but little or no change in the time-topeak. Figure $6 C$ summarizes measurements of the amplitude of the filter at high contrast relative to that at low contrast for $17 \mathrm{oFF}$ bipolars and 25 on bipolars, all measured under voltage clamp. Contrast had a slightly larger effect on the amplitude of the light responses of ofF bipolars than on bipolars. Figure $6 D$ summarizes measurements of the time-to-peak of the linear filter at high contrast relative to that at low contrast. The change in response kinetics was clear in OFF bipolars and small or absent in ON bipolars. A similar asymmetry between the effect of contrast on the responses of ON and OFF bipolars was observed in currentclamp recordings. This asymmetry contributes to an ON-OFF asymmetry in the light responses of salamander retinal ganglion cells (Chander and Chichilnisky, 1999; Kim and Rieke, 2001) (see Discussion).

\section{Contrast adaptation affects rod-and cone-mediated responses}

Contrast affected the amplitude and kinetics of the bipolar responses over a wide range of light intensities. Thus, contrast adaptation acted on signals from both rod and cone photoreceptors. Rod-dominated responses were studied using $470 \mathrm{~nm}$ light at mean intensities of $4-40$ photons $\mu \mathrm{m}^{-2} \mathrm{sec}^{-1}$, too dim to produce responses in the cones. Cone-dominated responses were studied using $640 \mathrm{~nm}$ light at mean intensities of 3,000-80,000 photons $\mu \mathrm{m}^{-2} \mathrm{sec}^{-1}$, light levels sufficient to saturate the rods. Contrast adaptation was studied by delivering 10 and $30 \%$ light inputs and measuring steady-state sensitivity using the static nonlinearity model. Figure 7 shows linear filters measured for rod- (Fig. 7A) and cone- (Fig. $7 B$ ) dominated responses in a voltage-clamped ofF bipolar cell. The corresponding static nonlinearities overlapped and hence did not contribute to contrast adaptation (data not shown). Rod-mediated responses were slower than cone-mediated responses, as expected from the slower kinetics of the photoreceptor responses themselves. However, increasing the contrast of the light input from 10 to $30 \%$ decreased the amplitude and the time-to-peak of the filter for both rod- and cone-mediated signals. Contrast affected the sensitivity of the bipolar cell responses for mean light levels as low as 4 photons $\mu \mathrm{m}^{-2} \mathrm{sec}^{-1}$ (three cells) and as high as 80,000 photons $\mu \mathrm{m}^{-2} \mathrm{sec}^{-1}$ (six cells). This indicates that contrast adaptation in photoreceptor-bipolar signal transfer is a general property of how signals are processed by the retinal circuitry.

\section{Mechanism of contrast adaptation in bipolar cells}

The effect of contrast on the sensitivity of bipolar cells and lack of an effect on the sensitivities of photoreceptors and horizontal cells (Fig. 3) indicates that contrast adaptation is mediated after signals are transferred to the bipolar cell. The experiments described below tested several possible mechanisms: (1) voltageactivated conductances in the bipolar soma (Mao et al., 1998); (2) amacrine feedback to the bipolar synaptic terminal (Maguire et al., 1989); (3) horizontal cell input to the bipolar dendrites
A. Rod dominated

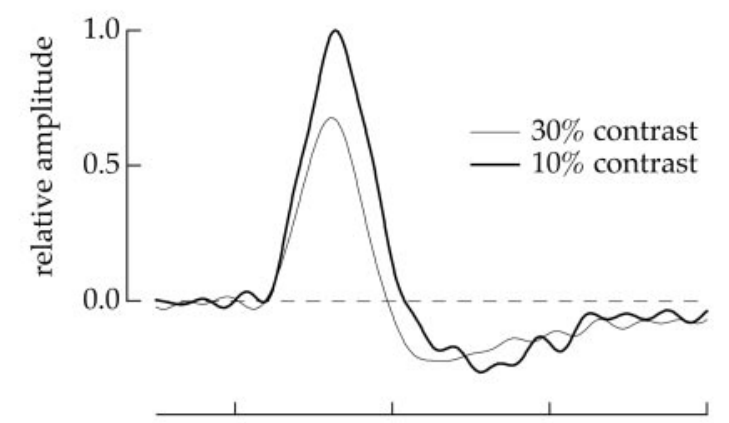

B. L cone dominated

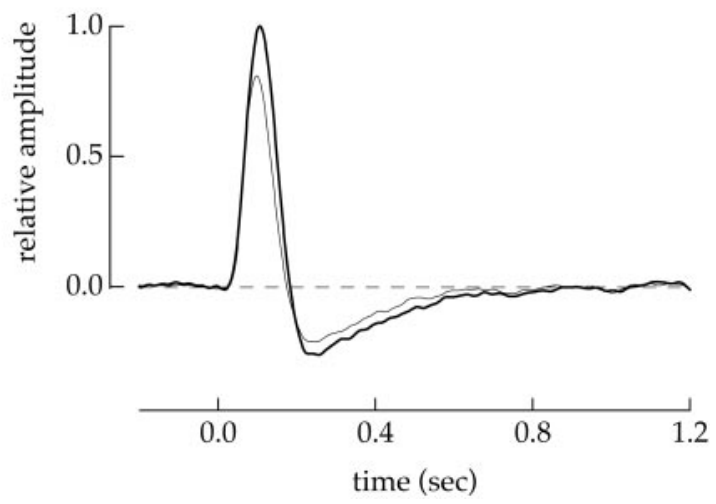

Figure 7. Contrast affected both rod- and cone-mediated responses. $A$, Linear filters for a voltage-clamped ofF bipolar cell for 10 and $30 \%$ contrast light inputs using $470 \mathrm{~nm}$ light at a mean intensity of 24 photons $\mu \mathrm{m}^{-2} \mathrm{sec}^{-1}$ and a bandwidth of $0-10 \mathrm{~Hz}$. The wavelength and low mean intensity favored responses of rods over those of cones. $B$, Linear filters for the same cell for 10 and $30 \%$ contrast light inputs using $640 \mathrm{~nm}$ light at a mean intensity of 18,800 photons $\mu \mathrm{m}^{-2} \mathrm{sec}^{-1}$ and a bandwidth of $0-30 \mathrm{~Hz}$. These conditions favored the responses of $\mathrm{L}$ cones over those of rods. The holding potential was $-60 \mathrm{mV}$, resulting in a current of -40 pA. Perforated-patch recording.

(Mangel, 1991); and (4) $\mathrm{Ca}^{2+}$-dependent mechanisms in the bipolar dendrites (Shiells and Falk, 1999; Nawy, 2000).

\section{Voltage-activated conductances in bipolar soma make a minimal contribution}

If voltage-activated conductances in the bipolar soma make a substantial contribution to contrast adaptation, the effect of contrast on the light response of a bipolar should differ when the bipolar voltage is free to change or held constant. The extent of contrast adaptation under current and voltage clamp was measured using the static nonlinearity model as in Figures 1 and 3 . Figure $8 A$ shows linear filters at 10 and $30 \%$ contrast for a voltage-clamped ofF bipolar cell. Contrast affected the amplitude and kinetics of the filter. Figure $8 B$ shows linear filters for current-clamp responses from the same cell. Contrast again affected the amplitude and kinetics of the filter, and the magnitude of these effects was similar to that observed under voltage clamp.

The extent of contrast adaptation with the membrane voltage clamped or free to change was compared in seven ofF bipolars and five on bipolars; collected results are shown in Figure 8, $C$ and $D$. Figure $8 C$ plots the change in the amplitude of the linear filter measured under voltage clamp against that measured under current clamp, with each point representing measurements from a 

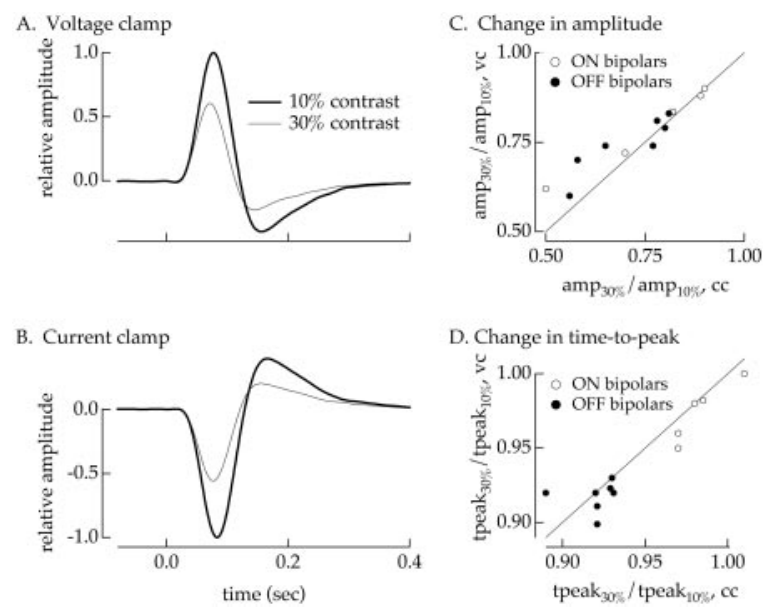

Figure 8. Contrast adaptation was similar under current and voltage clamp. $A$, Linear filters for a voltage-clamped off bipolar cell for 10 and $30 \%$ contrast light inputs. Holding potential was $-60 \mathrm{mV}$, resulting in a current of $-90 \mathrm{pA}$. $B$, Linear filters for the same cell from current-clamp responses. Holding current was $-50 \mathrm{pA}$, resulting in a voltage of $-48 \mathrm{mV}$. Mean light intensity, 16,100 photons $\mu \mathrm{m}^{-2} \mathrm{sec}^{-1}$ using $640 \mathrm{~nm}$ LED. $C$, Collected results on the change in amplitude of the filter from voltageclamp ( $y$-axis) and current-clamp ( $x$-axis) responses. Each point represents one cell. The line has a slope of 1 and hence is the expectation of contrast adaptation was the same under current and voltage clamp. $D$, Collected results on the change in time-to-peak of the filter. Perforatedpatch recording.

single cell as in Figure $8, A$ and $B$. Figure $8 D$ compares the change in time-to-peak of the filters measured under voltage and current clamp. In each case, the points cluster near the line of identity, indicating that the effect of contrast on the amplitude and kinetics of the light responses of bipolar cells was similar under current and voltage clamp. These experiments show that voltage-activated conductances in the bipolar soma make little or no contribution to contrast adaptation.

\section{Contrast adaptation persists without amacrine feedback}

To test whether the effect of contrast could be attributable to amacrine feedback to the bipolar synaptic terminal, contrast adaptation was measured with the amacrine feedback working normally and with it suppressed. Amacrine feedback was suppressed with picrotoxin and strychnine, inhibitors of the GABA (Maguire et al., 1989) and glycine (Maple and Wu, 1998; Cook et al., 2000) receptors on the bipolar synaptic terminal. A substantial increase in the amplitude of the light responses of amacrine and ganglion cells confirmed that that picrotoxin and strychnine were effective in altering inhibition from amacrine cells (data not shown).

The effect of contrast on the amplitude and kinetics of the light response of a bipolar persisted in the presence of picrotoxin and strychnine. Figure 9, $A$ and $B$, compares the extent of contrast adaptation in a voltage-clamped ofF bipolar cell superfused with normal Ringer's solution (Fig. 9A) or with Ringer's solution containing $150 \mu \mathrm{M}$ picrotoxin and $5 \mu \mathrm{M}$ strychnine (Fig. 9B). Picrotoxin and strychnine did not substantially alter the effect of contrast. Results from 13 bipolars in which contrast adaptation was measured with and without amacrine feedback are summarized in Figure $9 C$, which plots the effect of contrast on the amplitude of the response of a cell in picrotoxin and strychnine $(y$-axis) against that in Ringer's solution ( $x$-axis). Each point represents measurements on a single cell. The points cluster
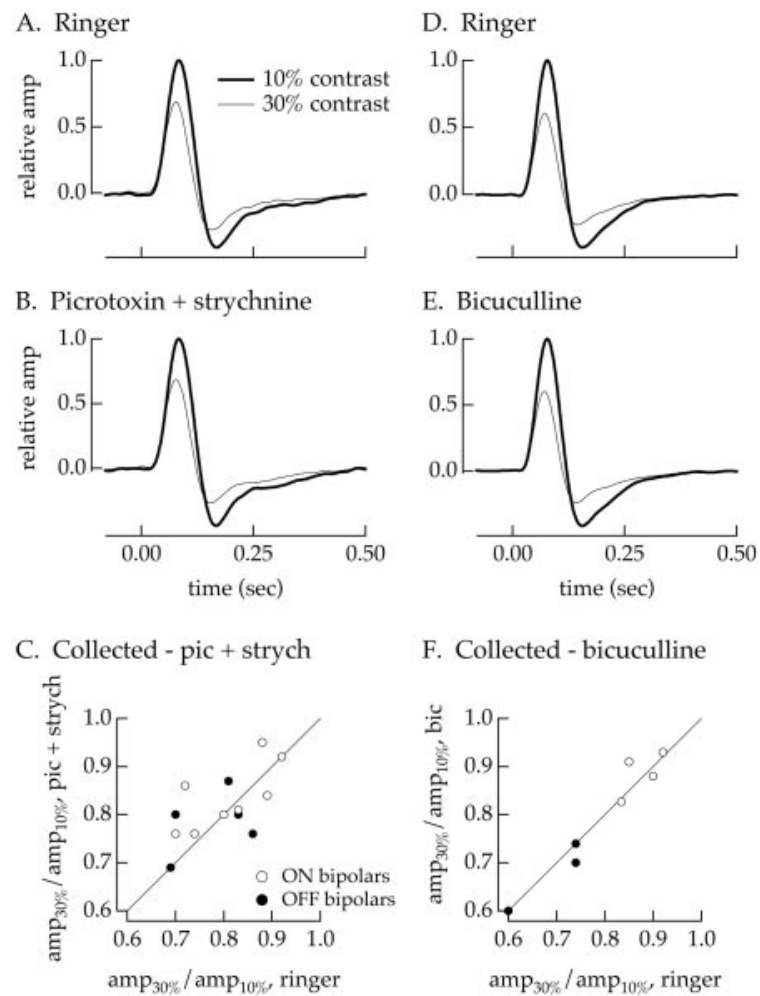

F. Collected - bicuculline

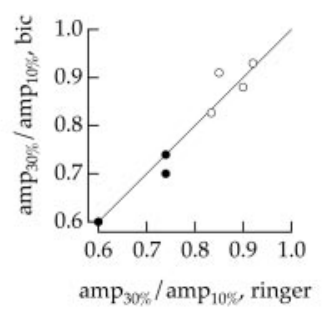

Figure 9. Amacrine and horizontal cells contributed little to contrast adaptation. $A$, Linear filters for a voltage-clamped ofF bipolar cell superfused in normal Ringer's solution for light inputs of 10 and $30 \%$ contrast. $B$, Linear filters for the same cell as in $A$ superfused in Ringer's solution containing $150 \mu \mathrm{M}$ picrotoxin and $5 \mu \mathrm{M}$ strychnine. Holding potential was $-60 \mathrm{mV}$, resulting in a current of $-60 \mathrm{pA}$. $C$, Collected results on the amplitude of the filter at $30 \%$ contrast relative to that at $10 \%$ contrast for 13 cells tested in both normal Ringer's solution and Ringer's solution containing picrotoxin and strychnine. Each point represents one cell as in $A$ and $B$. The line has a slope of 1 and thus represents the expectation if picrotoxin and strychnine had no effect on contrast adaptation. $D$, Linear filters for a voltage-clamped oFF bipolar in normal Ringer's solution. $E$, Linear filters for the same cell as in $D$ superfused in Ringer's solution containing $5 \mu \mathrm{M}$ bicuculline. Holding potential was $-60 \mathrm{mV}$, resulting in a current of $-30 \mathrm{pA} . F$, Collected results on amplitude of the filter at $30 \%$ contrast relative to that at $10 \%$ contrast for seven cells tested in both normal Ringer's solution and Ringer's solution containing bicuculline. All were perforated-patch recordings. Mean light intensity, 17,200 photons $\mu \mathrm{m}^{-2} \mathrm{sec}^{-1}$ using $640 \mathrm{~nm}$ LED; bandwidth, 0-30 Hz.

around the line of identity, indicating that contrast adaptation was similar in the two cases. The average amplitude of the filter at high contrast relative to that at low contrast was $0.80 \pm 0.02$ (mean \pm SEM) in normal Ringer's solution and $0.82 \pm 0.02$ with amacrine feedback suppressed. Thus, contrast adaptation was affected little when amacrine feedback to the bipolar terminal was suppressed, and most or all of the adaptation was attributable to other mechanisms.

\section{Contrast adaptation persists when horizontal inputs to bipolars are suppressed}

To test whether the effect of contrast could be attributable to horizontal cell input to the bipolar dendrites, contrast adaptation was compared before and after suppressing the horizontal-bipolar synapse with bicuculline, an inhibitor of GABA receptors on the bipolar dendrites. The effect of contrast was essentially unchanged by suppression of horizontal input to bipolars.

Figure $9, D$ and $E$, compares the extent of contrast adaptation 
of a voltage-clamped OFF bipolar cell superfused with normal Ringer's solution (Fig. 9D) or with Ringer's solution containing 5 $\mu \mathrm{M}$ bicuculline (Fig. 9E). Contrast adaptation was similar in the two conditions. Figure $9 F$ collects results from seven such experiments, plotting the effect of contrast on the amplitude of the response of a cell in bicuculline ( $y$-axis) against that in Ringer's solution ( $x$-axis). Contrast adaptation was essentially unchanged in the presence of bicuculline. The average amplitude of the filter at high contrast relative to that at low contrast in these seven cells was $0.80 \pm 0.05$ (mean $\pm \mathrm{SEM}$ ) in both Ringer's solution and bicuculline. Thus, horizontal cell input to bipolars does not make a substantial contribution to contrast adaptation.

\section{$\mathrm{Ca}^{2+}$ buffers eliminate contrast adaptation in OFF bipolars}

The experiments of Figure 9 show that contrast adaptation persists when a bipolar cell is voltage clamped and amacrine feedback to the bipolar terminal is suppressed. Under these conditions, the voltage in the axon terminal should not change, and thus conductances in the axon terminal do not contribute significantly to contrast adaptation. The similarity of contrast adaptation under current and voltage clamp (Fig. 8) indicates that conductances in the soma do not make significant contributions. Thus, Figures 8 and 9 indicate that most of the contrast adaptation in the light response of a bipolar is generated in its dendrites.

Several studies have identified $\mathrm{Ca}^{2+}$-dependent gain controls in the dendrites of on bipolar cells (Shiells and Falk, 1999; Nawy, 2000). To test whether such a mechanism might contribute to contrast adaptation, changes in $\mathrm{Ca}^{2+}$ were suppressed by dialyzing a bipolar cell with a high concentration of $\mathrm{Ca}^{2+}$ buffer and measuring the consequences for contrast adaptation. The $\mathrm{Ca}^{2+}$ buffer and total $\mathrm{Ca}^{2+}$ in the dialyzing solution were increased by the same factor to keep the free $\mathrm{Ca}^{2+}$ concentration constant. HEDTA and diBromoBAPTA ( $\mathrm{Br}_{2}$ BAPTA) were used as $\mathrm{Ca}^{2+}$ buffers because they have a relatively low affinity for $\mathrm{Ca}^{2+}$ and thus are not likely to become fully $\mathrm{Ca}^{2+}$ bound.

Increasing the $\mathrm{Ca}^{2+}$ buffer concentration eliminated contrast adaptation in OFF, but not oN, bipolars. The effect of contrast on the gain and kinetics of the light response of a cell was measured using the static nonlinearity model (Fig. 1). Figure $10 \mathrm{~A}$ shows linear filters at 10 and $30 \%$ contrast for a voltage-clamped ofF bipolar dialyzed with a solution containing $1 \mathrm{~mm}$ HEDTA. As for perforated-patch recordings, contrast affected the amplitude and kinetics of the filter. Figure $10 \mathrm{~B}$ shows filters for a voltageclamped off bipolar dialyzed with a solution containing $10 \mathrm{~mm}$ HEDTA. In this case, contrast had little or no effect on the amplitude or kinetics of the filter. Results from ofF bipolars dialyzed with high and low concentrations of $\mathrm{Ca}^{2+}$ buffers are summarized in Figure $10 \mathrm{C}$ and compared with the extent of contrast adaptation in cells with native $\mathrm{Ca}^{2+}$ buffers (perforatedpatch recordings). All cells in which $\mathrm{Ca}^{2+}$ changes were suppressed with high $\mathrm{Ca}^{2+}$ buffer concentrations showed essentially no contrast adaptation.

Contrast adaptation in on bipolars had little or no dependence on the $\mathrm{Ca}^{2+}$ buffer concentration. Figure $10 D$ shows linear filters at 10 and $30 \%$ contrast for a voltage-clamped on bipolar dialyzed with a solution containing $1 \mathrm{~mm}$ HEDTA. Figure $10 E$ shows filters for a voltage-clamped on bipolar dialyzed with a solution containing $10 \mathrm{~mm}$ HEDTA. In both cases, the sensitivity of the light response of a cell decreased with increases in contrast. Figure $10 \mathrm{~F}$ collects results from on bipolars dialyzed with high and low concentrations of $\mathrm{Ca}^{2+}$ buffer and with native buffers intact. Contrast adaptation was similar in all three conditions.
A. OFF bipolar, $1 \mathrm{mM}$ HEDTA

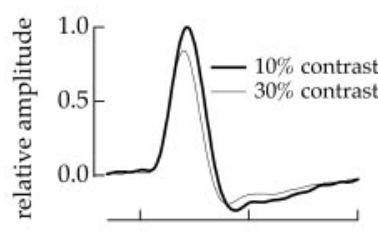

B. OFF bipolar, 10mM HEDTA
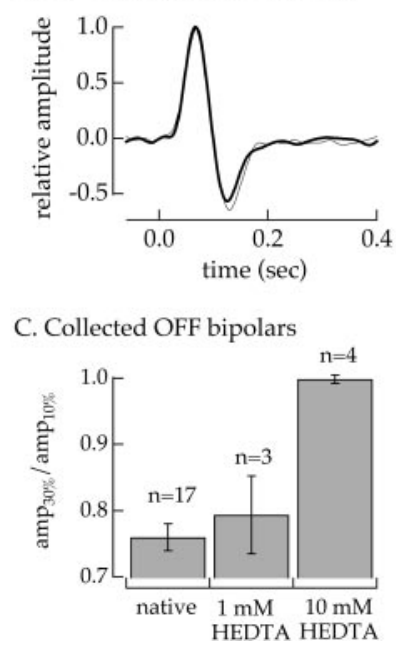

D. ON bipolar, $1 \mathrm{mM}$ HEDTA

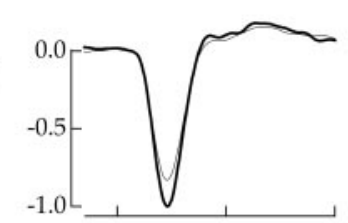

E. ON bipolar, 10mM HEDTA

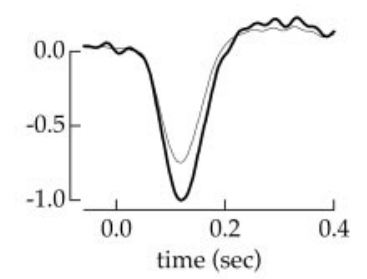

F. Collected ON bipolars

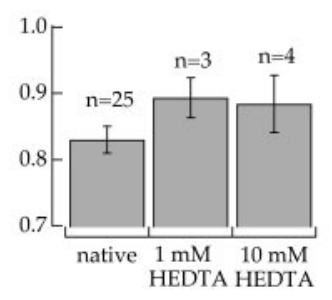

Figure 10. High concentrations of $\mathrm{Ca}^{2+}$ buffers suppress contrast adaptation in OFF, but not ON, bipolars. Contrast adaptation was compared in whole-cell recordings from bipolar cells dialyzed with internal solutions containing either 1 or $10 \mathrm{mM}$ of the $\mathrm{Ca}^{2+}$ buffer HEDTA. The total $\mathrm{Ca}^{2+}$ in the internal solutions was changed along with the $\mathrm{Ca}^{2+}$ buffer concentration to keep the free $\mathrm{Ca}^{2+}$ constant. $A$, Linear filters for 10 and $30 \%$ contrast light inputs for a voltage-clamped ofF bipolar dialyzed with $1 \mathrm{~mm}$ HEDTA. Holding potential was $-60 \mathrm{mV}$, resulting in a current of -50 pA. $B$, Filters for a voltage-clamped ofF bipolar dialyzed with $10 \mathrm{~mm}$ HEDTA. Holding potential was $-60 \mathrm{mV}$, resulting in a current of -40 pA. $C$, Collected results from ofF cells on the effect of contrast on the filter amplitude for perforated-patch recordings (native) and whole-cell recordings from cells dialyzed with 1 and $10 \mathrm{~mm}$ HEDTA. All were voltage-clamp recordings. $D$, Filters for a voltage-clamped oN bipolar dialyzed with $1 \mathrm{~mm}$ HEDTA. Holding potential was $-60 \mathrm{mV}$, resulting in a current of $-70 \mathrm{pA}$. $E$, Filters for a voltage-clamped on bipolar dialyzed with $10 \mathrm{~mm}$ HEDTA. Holding potential was $-60 \mathrm{mV}$, resulting in a current of -40 pA. F, Collected results from on cells. Mean light intensity, 18,500 photons $\mu \mathrm{m}^{-2} \mathrm{sec}^{-1}$ using $640 \mathrm{~nm}$ LED; bandwidth, 0-30 Hz.

Contrast adaptation also persisted in voltage-clamped on bipolar cells dialyzed with a solution containing $5 \mathrm{~mm} \mathrm{Br}_{2}$ BAPTA (data not shown). In eight cells dialyzed with $\mathrm{Br}_{2} \mathrm{BAPTA}$, the amplitude of the linear filter for $30 \%$ contrast inputs relative to $10 \%$ contrast inputs was $0.81 \pm 0.04$ (mean \pm SEM), again similar to the extent of contrast adaptation with the native $\mathrm{Ca}^{2+}$ buffers intact.

The results summarized in Figure 10 indicate that $\mathrm{Ca}^{2+}$. dependent mechanisms in the bipolar dendrites contribute to contrast adaptation in OFF, but not ON, bipolars. This difference may help explain why ofF bipolar cells adapt more strongly to contrast changes than on bipolars (Fig. 6).

\section{DISCUSSION}

The experiments described here lead to three conclusions about contrast adaptation in salamander bipolar cells: (1) bipolar cells, but not horizontal cells or photoreceptors, adapt to temporal contrast; (2) contrast adaptation in the bipolars has a relatively 
fast onset and offset; and (3) the functional properties of contrast adaptation in ON and OFF bipolars differ. The properties of contrast adaptation in salamander bipolar cells are discussed below and compared with adaptation in retinal ganglion cells.

\section{Contrast gain and contrast adaptation}

Contrast adaptation in signal transfer from photoreceptors to bipolars serves an important role in protecting against saturation. For contrast steps about a steady light level, the contrast gain of salamander bipolar cells is 5-10 times higher than that of cones (Burkhardt and Fahey, 1998) (Figs. 2, 3). Thus, without adaptation, fluctuating light inputs with a contrast of 5-10\% would lead to significant saturation of the bipolar responses; such saturation would compromise encoding of visual inputs. Contrast adaptation may be a general feature of signal processing in bipolar cells. In rabbit, altering the contrast in the surround of the receptive field of a ganglion cell does not affect the gain of the receptive field center, suggesting that mammalian bipolar cells, which provide the receptive field center, also adapt to contrast (Brown and Masland, 2001).

\section{Time course of onset and offset in bipolar and ganglion cells}

After an increase in contrast, the onset of adaptation in the currents measured at the ganglion cell soma included fast (1-2 sec) and slow (10-20 sec) components (Kim and Rieke, 2001), suggesting that at least two distinct mechanisms contribute. The fast component in the ganglion cell currents accounted for a $20-30 \%$ reduction in the sensitivity when the contrast was increased by a factor of three (Kim and Rieke, 2001). In bipolar cells, the onset of contrast adaptation was restricted to a fast (1-2 sec) component. A threefold increase in contrast reduced the bipolar sensitivity by $20-25 \%$, similar to the reduction in the sensitivity of a ganglion cell attributable to the fast-onset component of contrast adaptation. Thus, adaptation in the bipolar cells can account for most or all of the fast-onset contrast adaptation seen in the currents at the ganglion cell soma. Bipolar cells did not show a substantial slow component of contrast adaptation, and hence this component must originate at a later stage in retinal processing.

The different temporal components of contrast adaptation likely play different functional roles in retinal signal processing. The slow onset form of contrast adaptation observed in the responses of retinal ganglion cells (Smirnakis et al., 1997) is well suited to dynamically adjust visual sensitivity to match the temporal and spatial structure of the light inputs. The fast-onset component of contrast adaptation seen in the bipolar cells and ganglion cells is likely to shape responses to single visual objects, e.g., objects moving through the receptive field of a cell (Berry et al., 1999). The fast-onset component of contrast adaptation in the output spike trains of a ganglion cell contains approximately equal contributions from adaptation in the bipolar cells and adaptation in spike generation in the ganglion cell itself (Kim and Rieke, 2001).

The onset and offset of contrast adaptation follow different time courses in both bipolars (Fig. 5) and ganglion cells (Smirnakis et al., 1997; Brown and Masland, 2001), with the offset of adaptation proceeding more slowly than the onset. The asymmetry between the time course of the onset and offset is in agreement with theoretical arguments about the ease with which increases and decreases in contrast can be detected from the response of a cell (DeWeese and Zador, 1998).

\section{Functional and mechanistic differences between oN and off bipolars}

The functional properties of contrast adaptation differed for oN and OFF bipolar cells (Fig. 6). Increases in contrast had a similar effect on the amplitude of the light responses in ON and OFF cells. Changes in contrast, however, had a much more pronounced effect on the kinetics of the response of OFF bipolars than ON bipolars. In salamander retinal ganglion cells, changes in contrast had a greater effect on both the amplitude and kinetics of the light response in OFF cells than oN cells (Chander and Chichilnisky, 1999, 2001; Kim and Rieke, 2001). Thus, some but not all of the ON-OFF asymmetry in the ganglion cells can be accounted for by the asymmetry in the bipolars.

In addition to the difference in functional properties, the mechanisms mediating contrast adaptation in ON and OFF bipolars differed (Fig. 10). In both cell types, contrast adaptation was mediated by mechanisms in the dendrites. In ofF bipolars, suppressing changes in $\mathrm{Ca}^{2+}$ eliminated contrast adaptation, indicating that a $\mathrm{Ca}^{2+}$-dependent gain control in the dendrites was responsible. In on bipolars, suppressing $\mathrm{Ca}^{2+}$ changes had little or no effect on contrast adaptation. Adaptation in ON bipolars could be mediated by desensitization of glutamate receptors or regulation of the second-messenger cascade coupling the receptors to channels (Nawy, 1999).

\section{Mean and contrast adaptation in the retina}

The output signals of retinal ganglion cells adapt to both the mean light intensity (for review, see Walraven et al., 1990) and the temporal contrast (for review, see Shapley, 1997; Meister and Berry, 1999). The extent to which mean and contrast adaptation operate independently has an important bearing on how vision adjusts to changes in the statistics of the light inputs.

At high light levels, the mean and contrast of a visual scene are primarily independent, with the mean determined primarily by the illuminating light source and the contrast by the distribution of reflectances in the scene. At low light levels, the mean and contrast of the light inputs cannot change independently because of quantal fluctuations in the incident photons. Indeed, the form of adaptation operating at the lowest light intensity is mediated by mechanisms in the retinal circuitry controlled by quantal fluctuations in the light input (Donner et al., 1990), likely the same mechanisms causing contrast adaptation at higher light levels.

Several observations suggest that adaptation to the mean light intensity and the fluctuations about the mean are primarily independent in the outer retina. First, photoreceptors contribute to adaptation to the mean light level (for review, see Walraven et al., 1990; Koutalos and Yau, 1996) but not to contrast adaptation (Fig. 3) (Sakai et al., 1995; Smirnakis et al., 1997). Second, $\mathrm{Ca}^{2+}$-dependent mechanisms in the dendrites of on bipolar cells contribute to mean but not contrast adaptation (Shiells and Falk, 1999) (Fig. 10). Third, results described here suggest that signal transfer from photoreceptors to bipolars can be described as a contrast-dependent linear filter in the bipolar dendrites followed by a static nonlinearity (Fig. 3). Consistent with this description, the static nonlinearity was much less pronounced in voltageclamp experiments than current-clamp experiments and thus appeared to be dominated by voltage-dependent conductances in the bipolar soma. This indicates that contrast adaptation must be produced by a change in the fluctuations of the bipolar response rather than a change in the mean response. 


\section{REFERENCES}

Albrecht DG, Farrar SB, Hamilton DB (1984) Spatial contrast adaptation characteristics of neurones recorded in the cat's visual cortex. J Physiol (Lond) 347:713-739.

Attwell D, Wilson M, Wu SM (1984) A quantitative analysis of interactions between photoreceptors in the salamander (Ambystoma) retina. J Physiol (Lond) 352:703-737.

Berry MJ, Brivanlou IH, Jordan TA, Meister M (1999) Anticipation of moving stimuli by the retina. Nature 398:334-338.

Brown SP, Masland RH (2001) Spatial scale and cellular substrate of contrast adaptation by retinal ganglion cells. Nat Neurosci 4:48-51.

Burkhardt DA, Fahey PK (1998) Contrast enhancement and distributed encoding by bipolar cells in the retina. J Neurophysiol 80:1070-1081.

Burkhardt DA, Fahey PK (1999) Contrast rectification and distributed encoding by ON-OFF amacrine cells in the retina. $\mathrm{J}$ Neurophysiol 261:1676-1688.

Capovilla M, Hare WA, Owen WG (1987) Voltage gain of the signal transfer from retinal rods to bipolar cells in the tiger salamander. J Physiol (Lond) 391:125-140.

Chander D, Chichilnisky EJ (1999) Contrast adaptation and gain changes in salamander and monkey retina. Soc Neurosci Abstr 25:1431.

Chander D, Chichilnisky EJ (2001) Adaptation to temporal contrast in primate and salamander retina. J Neurosci, in press.

Chichilnisky EJ (2001) A simple white noise analysis of neuronal light responses. Network 12:199-213.

Cook PB, Lukasiewicz PD, McReynolds JS (2000) GABA $_{C}$ receptors control adaptive changes in a glycinergic inhibitory pathway in salamander retina. J Neurosci 20:806-812.

DeWeese M, Zador A (1998) Asymmetric dynamics in optimal variance adaptation. Neural Comput 10:1179-1202.

Donner K, Copenhagen DR, Reuter T (1990) Weber and noise adaptation in the retina of the toad Bufo marinus. J Gen Physiol 95:733-753.

Kim KJ, Rieke F (2001) Temporal contrast adaptation in the input and output signals of salamander retinal ganglion cells. J Neurosci 21:287-299.

Koutalos Y, Yau K-W (1996) Regulation of sensitivity in vertebrate rod photoreceptors by calcium. Trends Neurosci 19:73-81.

Maguire G, Lukasiewicz P, Werblin F (1989) Amacrine cell interactions underlying the response to change in the tiger salamander retina. J Neurosci 9:726-735

Mangel SC (1991) Analysis of the horizontal cell contribution to the receptive field surround of ganglion cells in the rabbit retina. J Physio (Lond) 442:211-234.

Mao BQ, Macleish PR, Victor JD (1998) The intrinsic dynamics of retinal bipolar cells isolated from tiger salamander. Vis Neurosci 15:425-438.

Maple BR, Wu SM (1998) Glycinergic synaptic inputs to bipolar cells in the salamander retina. J Physiol (Lond) 506:731-744.

Meister M, Berry MJ (1999) The neural code of the retina. Neuron 22:435-450.

Nawy S (1999) The metabotropic receptor mGluR6 may signal through $\mathrm{G}_{\mathrm{o}}$ but not phosphodiesterase, in retinal bipolar cells. J Neurosci 19:2938-2944

Nawy S (2000) Regulation of the on bipolar cell mGluR6 pathway by $\mathrm{Ca}^{2+}$. J Neurosci 20:4471-4479.

Ohzawa I, Sclar G, Freeman RD (1985) Contrast gain control in the cat's visual system. J Neurophysiol 54:651-667.

Sakai HM, Wang JL, Naka K (1995) Contrast gain control in the lower vertebrate retinas. J Gen Physiol 105:815-835.

Sanchez-Vives MV, Nowak LG, McCormick DA (2000) Membrane mechanisms underlying contrast adaptation in cat area 17 in vivo. J Neurosci 20:4267-4285.

Schwartz EA (1976) Electrical properties of the rod syncytium in the retina of the turtle. J Physiol (Lond) 257:379-406.

Shapley R (1997) Retinal physiology: adapting to the changing scene. Curr Biol 7:R421-R423.

Shiells RA, Falk G (1999) A rise in intracellular $\mathrm{Ca}^{2+}$ underlies light adaptation in dogfish retinal "on" bipolar cells. J Physiol (Lond) 514:343-350

Smirnakis SM, Berry MJ, Warland DK, Bialek W, Meister M (1997) Retinal processing adapts to image contrast and spatial scale. Nature 386:69-73.

Victor JD (1987) The dynamics of the cat retinal X cell centre. J Physiol (Lond) 386:219-246.

Walraven J, Enroth-Cugell C, Hood DC, MacLeod DIA, Schnapf JL (1990) The control of visual sensitivity. In: Visual perception: the neurophysiological foundations (Spillmann L, Werner SJ, eds), pp 53-101. San Diego: Academic.

Wiener N (1949) Extrapolation, interpolation and smoothing of stationary time series. Cambridge, MA: MIT.

Wu SM, Gao F, Maple BR (2000) Functional architecture of synapses in the inner retina: segregation of visual signals by stratification of bipolar cell axon terminals. J Neurosci 20:4462-4470. 